[Research Note]

\title{
Bimodal Porous Silica Prepared by Pore-filling of Silica Sol
}

\author{
Yi ZhAng, Yoshiharu YoneYAMA, and Noritatsu TsUBAKI* \\ Dept. of Material System and Life Science, School of Engineering, Toyama University, \\ Gofuku 3190, Toyama 930-8555, JAPAN \\ (Received December 19, 2002)
}

\begin{abstract}
A silica with bimodal pore structures was prepared by a simple method of introducing silica sol into the controlled large pores of original silica gel. The pores of the bimodal pore silica were distributed into two distinct pore sizes that could be accurately controlled. The increased BET surface area and the decreased pore volume of the obtained bimodal pore supports, as compared to those of the original silica gel, indicated that the particles of silica sols formed small pores inside the original large pores of silica gel, resulting in formation of the bimodal pore structure silica support. Both pore sizes could be controlled, as the large pores originated from tail-made pellet while mesopore size was equal to the diameter of sol particles regardless of sol concentration during catalyst support preparation.
\end{abstract}

\section{Keywords}

Bimodal pore structure, Silica, BET surface area, Pore volume, Pore size distribution

\section{Introduction}

Silica is widely used for catalyst support, as it is inexpensive, reasonably thermally stable and chemically inert. Furthermore, silica can provide a wide range of surface areas and porosities suitable for various catalytic applications. It is now generally accepted that the synthesis of mesoporous silica, such as MCM-41 and FSM-16, usually involves the formation of ion pairs between the oligomeric silicate species and surfactant ions, and the subsequent self-assembly of these ion pairs into ordered silicate-surfactant composites ${ }^{1}$. However, only uniform pore sizes can be formed in the obtained silica by this type of method. In general, the silica supports with small pore sizes have the large specific surface area, contributing to high dispersion of supported metal. In contrast, large pore size or small particle size of silica is usually favored to avoid diffusion problems. Supports with large pore size, showing advantage in the inside-pore diffusion efficiency, obviously have low specific surface area and are not beneficial to disperse supported metal, leading to low metal dispersion and low catalytic activity. A support with a bimodal pore structure has excellent advantages for solving this contradiction because the large pores provide rapid transportations of reactant and product molecules; meanwhile the small pores provide a large surface area simultaneously. Therefore, the bimodal

* To whom correspondence should be addressed.

* E-mail: tsubaki@eng.toyama-u.ac.jp pore support, which has both large and small pores, has high efficiency for molecular diffusion and for dispersion of active metal, as theoretically expressed by Levenspiel $^{2)}$.

Inui et al. developed a kind of bimodal $\mathrm{Ni} / \mathrm{SiO}_{2}$ catalyst utilizing a very strong acidic corrosion function of aqua regia ${ }^{3}$. This kind of catalyst exhibited high activity for methanation of $\mathrm{CO}_{2}$. Inoue et al. found an alcohothermal treatment method of gibbsite to prepare the bimodal alumina support, using various alcohols. For this kind of alumina, the micropores were not detected and the mesopores of $20 \mathrm{~nm}$ range were detected $^{4}$. These methods are only applicable to some specific oxide supports. The large pore size for the obtained bimodal catalyst support by these methods is too large such as several hundred nanometer. In order to develop a simple and general method for preparation of functional bimodal support with both large pores and mesopores, and to control the pore sizes, especially large pore size, precisely, a new method using silica gel with large pore of the desired size and silica sol for generating small pore is proposed here. On the other hand, this method can be expanded to prepare various bimodal structure catalyst supports with different chemical compositions as it is possible to change the combination of large-pore gel and sol. The present authors previously reported that $\mathrm{ZrO}_{2}-\mathrm{SiO}_{2}$ bimodal catalyst, which used a $\mathrm{ZrO}_{2}-\mathrm{SiO}_{2}$ bimodal support prepared by this method, exhibited significantly catalytic activity in slurry-phase Fischer-Tropsch synthesis, due to the spatial and chemical effects of bimodal pore sup- 
Table 1 Characterization of Silica Bimodal Supports Prepared from $\mathrm{SiO}_{2} \mathrm{Gel}$ and Sol

\begin{tabular}{lccccr}
\hline \multicolumn{1}{c}{ Support } & $\begin{array}{c}\text { Sol content } \\
{[\mathrm{wt} \%]}\end{array}$ & $\begin{array}{c}\mathrm{SiO} \text { loading } \\
{[\mathrm{wt} \%]}\end{array}$ & $\begin{array}{c}\text { BET } \\
{\left[\mathrm{m}^{2} / \mathrm{g}\right]}\end{array}$ & $\begin{array}{c}\text { Pore diameter } \\
{[\mathrm{nm}]}\end{array}$ & $\begin{array}{c}\text { Pore volume for mesopore } \\
{[\mathrm{m} l / \mathrm{g}]}\end{array}$ \\
\hline Q-50 & 0 & 0.0 & 70 & 50.0 & 0 \\
Silica bimodal A1 & 5 & 5.6 & 88 & $6.0-45$ & 0.17 \\
Silica bimodal A2 & 10 & 11.2 & 106 & $6.0-45$ & 0.20 \\
Silica bimodal A3 & 20 & 22.5 & 132 & $6.0-45$ & 0.65 \\
\hline
\end{tabular}

Calcined at $873 \mathrm{~K}$ for $2 \mathrm{~h}$.

port ${ }^{5}$. For instance, $\mathrm{Al}_{2} \mathrm{O}_{3}-\mathrm{SiO}_{2}$ (large pore: $\mathrm{Al}_{2} \mathrm{O}_{3}$, small pore: $\mathrm{SiO}_{2}$ ), and $\mathrm{SiO}_{2}-\mathrm{Al}_{2} \mathrm{O}_{3}$ (large pore: $\mathrm{SiO}_{2}$, small pore: $\mathrm{Al}_{2} \mathrm{O}_{3}$ ) bimodal pore structures are also possible.

\section{Experimental}

The bimodal pore support was prepared by incipientwetness impregnation of commercially available silica gel (CARiACT Q-50, Fuji-Silysia Chemical Ltd., specific surface area: $70 \mathrm{~m}^{2} \mathrm{~g}^{-1}$, pore volume: $1.2 \mathrm{~cm}^{3} \mathrm{~g}^{-1}$, pellet size: $74-590 \mu \mathrm{m}$ and pore diameter: $50 \mathrm{~nm}$ ) with silica sols (Snowtex XS, Nissan Chemical Industries, Ltd.) of different concentration. After the impregnation, the support was vacuumed for $1 \mathrm{~h}$, and then washed 4 times with $100 \mathrm{ml}$ water. At last, the samples were calcined in air at $873 \mathrm{~K}$ for $2 \mathrm{~h}$. The aqueous sol of silica had the $\mathrm{pH}$ of 9.0-10.0 and the silica content of $20 \mathrm{wt} \%$. The silica particle size of the sol was $5 \mathrm{~nm}$.

Pore size distribution, BET surface area and pore volume were determined by the measuring instrument for surface area and pore size of porous materials (Shimadzu ASAP 2000) using nitrogen as the absorbate. Thermal gravimetric analysis (TGA) was conducted using a Shimadzu DTG-60 instrument. The samples before calcination were placed in the furnace and heated in air to the desired temperature, 873 $\mathrm{K}$, at a heating rate of $10 \mathrm{~K} \mathrm{~min}^{-1}$ and then held at the final temperature for $2 \mathrm{~h}$.

\section{Results and Discussion}

As summarized in Table 1, for the obtained bimodal pore supports prepared with different silica loading, the BET surface area increased from $70 \mathrm{~m}^{2} \mathrm{~g}^{-1}$ of the original silica gel Q-50 to $132 \mathrm{~m}^{2} \mathrm{~g}^{-1}$ of the bimodal support with $22.5 \mathrm{wt} \%$ silica loading. Furthermore, it increased with increased silica loading. The pore volume was lower than that of the original silica gel Q-50, from $1.2 \mathrm{~cm}^{3} \mathrm{~g}^{-1}$ for silica Q-50 to $0.4 \mathrm{ml} / \mathrm{g}$ for bimodal pore support with $22.5 \mathrm{wt} \%$ silica loading, and decreased with the increased silica loading. On the other hand, different bimodal supports with different silica loading showed similar pore distribution, as the pore size located at $6 \mathrm{~nm}$ and $45 \mathrm{~nm}$, unlike silica gel
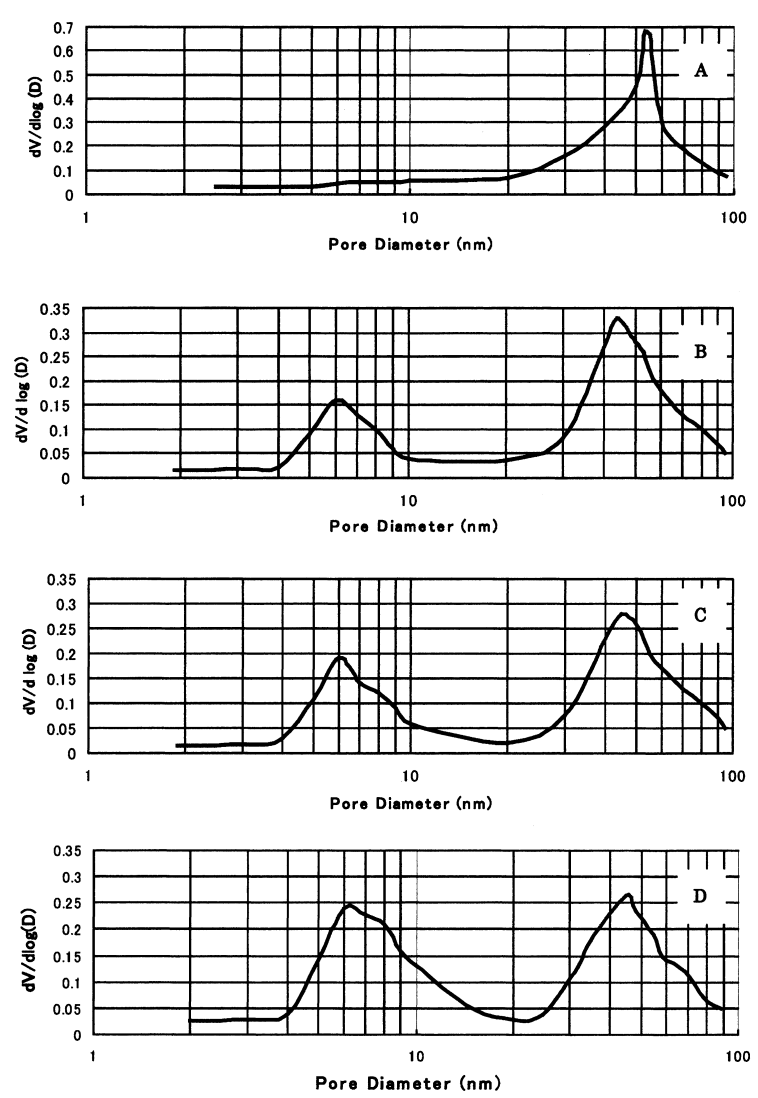

A: Q-50, B: Bimodal support A1, C: Bimodal support A2, D: Bimodal support A3.

Fig. 1 Pore Size Distributions of Q-50 and Bimodal Support

Q-50 with uniformly distributed $50 \mathrm{~nm}$ pores. The large pores of silica gel Q-50 slightly decreased from original 50 to $45 \mathrm{~nm}$.

Pore distribution of the obtained bimodal pore supports and silica gel Q-50 are shown in Fig. 1. It is clearly proved that the obtained bimodal pore support contains distinctly distributed two kinds of pores, according to the bimodal pore structure. The increased BET surface area and the decreased pore volume also indicated that the particles of silica sols entered the large pores of Q-50, and deposited on the inner wall of Q-50 to form the small pores. If the silica particles deposited at the entrance of large pores of Q-50, the large pores of bimodal support would be 


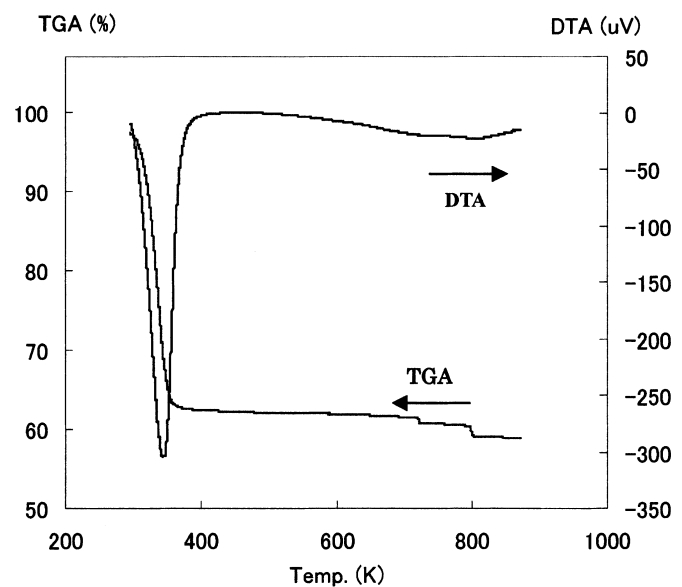

Fig. 2 The TG and DTA Profiles of Bimodal Support A2

blocked, and the BET surface area of the bimodal pore support would decrease significantly. These findings indicate that silica from the sols entered the large pores of Q-50 gel and the bimodal pore support was formed.

It was reported that the particles of silica sol aggregated easily if vapor coexisted in the calcination step, because the silanol on the surface of silica particles is easy to be produced, contributing to movement of the particles of silica sol ${ }^{6)}$. Based on this, the samples of the bimodal supports were calcined at $873 \mathrm{~K}$ for $2 \mathrm{~h}$ directly without drying after impregnation, to improve the aggregation of silical sol particles with the coexisting vapor. Concerning the TGA of the calcination step of the bimodal pore support sample, as shown in Fig. 2, an endothermic weight loss was found at 355 $\mathrm{K}$, due to the loss of solvent water. After vaporization of solvent water, the dehydration of silanol occurred on the surface of the silica particles, resulting in aggregation of the silica particles to form the $6 \mathrm{~nm}$ mesopores inside the large pores of the silica gel Q-50. The endothermic weight loss between $727 \mathrm{~K}$ and $800 \mathrm{~K}$ was attributed to this dehydration of the silanol groups of the particles of silica sol.

For a mass of agglomerate of spherical particles, the specific surface area $(S)$ is given by Eq. (1):

$$
S=3 / \rho r
$$

where $r$ and $\rho$ are the radius and density of the particles, respectively. Based on this, the specific surface area of the silica bimodal pore support can be determined by the particle size of silica sol, so a sol with favorite particle size can be chosen to form a desired bimodal pore support. Furthermore, if the diameter of the primary particle in sol is $D$, the pore size, produced by this kind of primary particles, is determined by the diameter $D$ and the agglutination of primary particles ${ }^{7}$. It will be $0.155 D, 0.414 D$ and $D$, when the primary par-
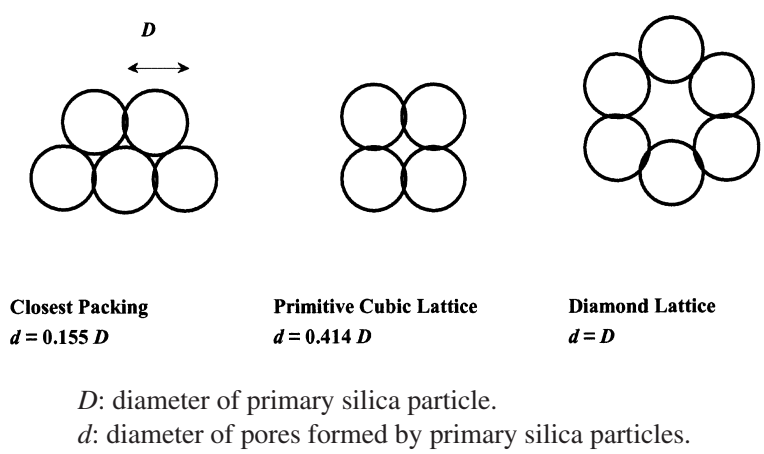

Fig. 3 Agglutination of Silica Primary Particles

ticles aggregate as closest packing, primitive cubic lattice and diamond lattice, respectively, as shown in Fig. 3.

In this study, the primary particle size of silica sol was $5 \mathrm{~nm}$, and formed new small pores with $6 \mathrm{~nm}$ diameter inside the large pores of silica gel Q-50. The more important point is that for the obtained silica bimodal pore supports, the newly-formed small pore size was $6 \mathrm{~nm}$, irrespective of the increased silica loading, as exhibited in Table 1. These findings indicated that the primary particles of silica sol aggregated as diamond lattice mainly, inside the large pores of silica Q-50 in the calcination step. If the primary particles mainly aggregated as closest packing or primitive cubic lattice, the size of newly-formed small pores would be smaller than the diameter of primary particle. These findings are important to control the mesopore size precisely. It was very convenient to determine the mesopore size and large pore at the same time, because mesopore size was equal to the diameter of sol particle irrespective of the concentration of the sol and the large pores were tailor-made. Furthermore, the specific surface area and pore structure of porous silica support were thermally stable. Therefore, the specific surface area and pore structure of the obtained bimodal supports were not influenced by the calcination temperature, which was $873 \mathrm{~K}$ in this study. Based on these facts, the bimodal silica with desired large pores and small pores can be formed by choosing a silica gel with suitable large pores and a silica sol with favorite particle size.

Meanwhile, a lot of oxides, such as zirconia or alumina, are used as chemical promoters but not spatial promoters to synthesize highly active silica-based catalyst ${ }^{8), 9)}$. By this method proposed in this article, it is considered that the multi-function bimodal supports can be formed, where besides spatial effect of bimodal pore structure, new chemical phenomenon or effect might appear with the hetero-atom formation between different oxides.

The preparation method of introducing oxide sols other than silica or zirconia into large-pore silica pellets 
is being developed.

\section{References}

1) Huo, Q., Margolese, D. I., Ciesla, U., Feng, P., Gier, T. E., Sieger, P., Leon, R., Petroff, P. M., Schiith, F., Stucky, G. D., Chem. Mater., 6, 1176 (1994).

2) Levenspiel, O., "Chemical Reaction Engineering," 2nd ed., Wiley, New York (1972), p. 496.

3) Inui, T., Funabiki, M., Suehiro, M., Sezume, T., J. Chem. Soc., Faraday Trans. 1, 75, 787 (1979).
4) Inoue, M., Kitamura, K., Inui, T., J. Chem. Tech. Biotechnol., 46, 233 (1989).

5) Zhang, Y., Yoneyama, Y., Tsubaki, N., Chem. Commun., 1216 (2002).

6) Iler, R., "Colloid Chemistry of Silica and Silicates," Cornell Univ. Press, (1955).

7) Johnson, M. F. L., Mooi, J., J. Catal., 10, 353 (1968).

8) Withers, H. P., Eliezer, K. F., Mitchell, J. W., Ind. Eng. Chem. Res., 29, 1807 (1990).

9) Takahashi, R., Sato, S., Sodesawa, T., Yabu, M., J. Catal., 200, 197 (2001).

要 旨

\section{シリカゾルのポアフィリングによるバイモダル細孔構造を有するシリカの調製}

張炎, 米山 嘉治, 椿範立

富山大学工学部物質生命システム工学科, 930-8555 富山市五福 3190

バイモダル細孔構造を有するシリカ触媒担体の簡単な調製法 を開発した。あらかじめ細孔径が決まった大きなポアを有する シリカゲルにシリカゾルを直接導入する方法である。得られた 担体はバイモダルな細孔径分布を示した。さらに元のシリカゲ ルと比ベ，バイモダル細孔担体の比表面積が増加し, 細孔容積 が減少した。これらの結果から, シリカゾルのナノ粒子からシ
リカゲルの大きなポアの内壁にメゾポアが形成され，バイモダ ル細孔構造が形成されたと考えられる。大きなポアのサイズは 元のシリカゲルの細孔径とほぼ等しく,メゾポアの細孔径は, 含浸させたゾルの濃度, 担持量とは関係なく, シリカゾルの粒 子径と同じであることが分かった。 